\title{
Un annuaire franco-allemand des médiévistes
}

\section{Pierre Monnet}

\section{OpenEdition}

\section{Journals}

Édition électronique

URL : http://journals.openedition.org/ifha/413

DOI : 10.4000/ifha.413

ISSN : 2198-8943

\section{Éditeur}

IFRA - Institut franco-allemand (sciences historiques et sociales)

\section{Édition imprimée}

Date de publication : 30 septembre 2012

Pagination : $91-92$

ISSN : 2190-0078

Référence électronique

Pierre Monnet, " UN ANNUAIRE fRANCo-ALlemand des MÉdiévistes 》, Revue de l'IFHA [En ligne],

4 | 2012, mis en ligne le 14 février 2013, consulté le 01 mai 2019. URL : http://

journals.openedition.org/ifha/413 ; DOI : 10.4000/ifha.413

Ce document a été généré automatiquement le 1 mai 2019.

(CIFHA 


\title{
Un annuaire franco-allemand des médiévistes
}

\author{
Pierre Monnet
}

1 L'IFHA (Pierre Monnet) et la chaire d'histoire médiévale du département de la faculté de Münster (Martin Kintzinger), à l'origine de la création à l'automne 2011 d'un forum interdisciplinaire des études françaises dans cette université, ont proposé aux deux communautés des médiévistes français et allemands, qui l'ont acceptée, la création d'un annuaire scientifique recensant les historiens de la période intéressés à figurer dans une base de données commune. Celle-ci a pour vocation d'inventorier les collègues intéressés par une coopération avec un homologue, un centre de recherche, un programme scientifique, un département universitaire dans sa période et son champ d'intérêt. En effet, en considération de l'attention croissante accordée aujourd'hui à l'internationalisation de la recherche et de l'enseignement supérieur, il a paru opportun de cartographier la coopération déjà existante entre les institutions scientifiques françaises et allemandes en matière d'histoire médiévale, afin d'encourager la définition et le développement de champs communs de recherche et de méthodes partagées. À cet égard, la connaissance réciproque des intérêts, des objets et des équipes de recherche respectifs constitue assurément une condition indispensable au développement des relations entre les deux communautés, à l'émergence de nouveaux projets et à la lisibilité des relations déjà tissées ou en cours de rapprochement.

2 Les entrées de cette base, en voie de constitution et dont la collecte d'informations devrait être achevée à l'été 2012 pour une mise en ligne avant la fin de l'année, consistent à répertorier dans un premier temps l'intérêt de principe que chacune ou chacun manifeste ou entend manifester à l'avenir envers le montage de parcours (cursus d'études franco-allemands, tels que ceux label lisés et financés par l'Université franco-allemande) ou de projets communs (ainsi des coopérations issues des appels à projets en sciences sociales et humaines entre l'Agence Nationale de la Recherche et la Deutsche Forschungsgemeinschaft). Il s'agit ensuite de savoir quelles coopérations occasionnelles ou pérennes existent ou pourraient exister entre les médiévistes français et allemands 
(conférences, colloques, invitations, séjours en qualité de professeurs invités, séminaires, écoles d'été). Il s'agit également de connaitre l'implication de telle ou tel dans une formation doc torale partagée (cotutelles et/ou collèges doctoraux franco-allemands) et d'établir la liste des thèses, des habilitations, des doctorants et des post-doctorants dirigés et encadrés quand leurs sujets concernent de près ou de loin l'histoire du voisin ou suppose une forte dimension franco-allemande, y compris sur le plan méthodologique. Sur le plan scientifique, cet annuaire souhaite aussi savoir dans quels champs ou autour de quelles problématiques la coopération est souhaitée, sur une question touchant ou impliquant l'histoire de l'autre, ou bien dans une dimension comparée. L'une des entrées interroge également le degré de maîtrise linguistique de la langue partenaire par les collègues volontaires pour entrer dans cette base. Une autre demande de citer 3 à 4 titres d'ouvrages, d'actes ou d'articles publiés pour peu qu'ils concernent l'histoire de l'autre.

Les concepteurs de cette base espèrent ainsi qu'un nouvel outil bilingue, biculturel et binational disponible en ligne pourra faire le compte des collègues ouverts à la coopération avec l'autre, des doctorants et des jeunes chercheurs actuellement engagés dans une recherche dialoguant avec l'autre pays, des manifestations légères et ponctuelles (colloques en cours ou à venir), des publications communes, ou encore des coopérations pérennes ou structurantes (séminaires partagés, cursus intégrés, collèges doctoraux, cotutelles de thèse) mises en œuvre entre les deux communautés de médiévistes.

\section{AUTEUR}

\section{PIERRE MONNET}

Pierre Monnet est directeur de l'IFHA. 